\title{
Literature Review of Potential Thermally Activated Heat Pump Cycles
}

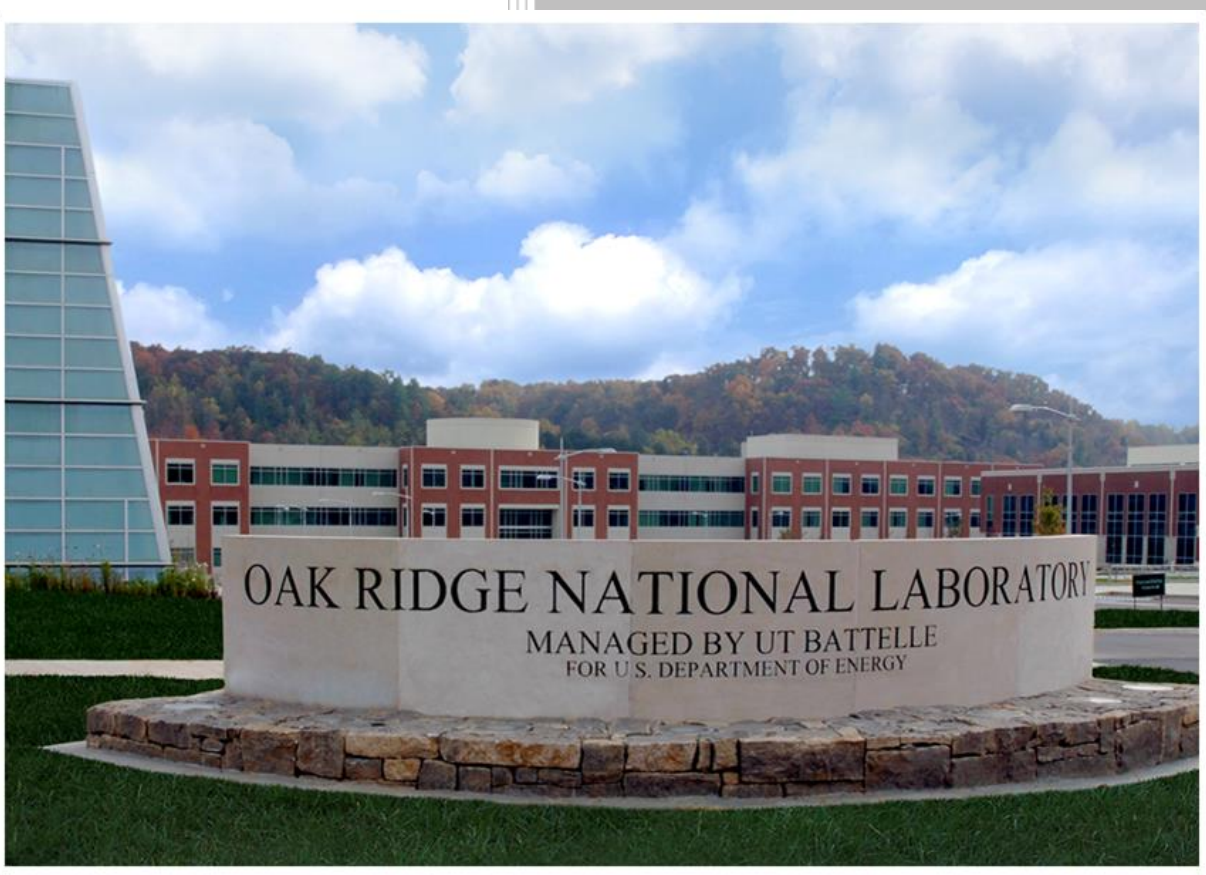

Approved for public release.

Distribution is unlimited. 


\title{
DOCUMENT AVAILABILITY
}

Reports produced after January 1, 1996, are generally available free via US Department of Energy (DOE) SciTech Connect.

Website www.osti.gov

Reports produced before January 1, 1996, may be purchased by members of the public from the following source:

\author{
National Technical Information Service \\ 5285 Port Royal Road \\ Springfield, VA 22161 \\ Telephone 703-605-6000 (1-800-553-6847) \\ TDD 703-487-4639 \\ Fax 703-605-6900 \\ E-mail info@ntis.gov \\ Website http://classic.ntis.gov/
}

Reports are available to DOE employees, DOE contractors, Energy Technology Data Exchange representatives, and International Nuclear Information System representatives from the following source:

Office of Scientific and Technical Information

PO Box 62

Oak Ridge, TN 37831

Telephone 865-576-8401

Fax 865-576-5728

E-mail reports@osti.gov

Website http://www.osti.gov/contact.html

This report was prepared as an account of work sponsored by an agency of the United States Government. Neither the United States Government nor any agency thereof, nor any of their employees, makes any warranty, express or implied, or assumes any legal liability or responsibility for the accuracy, completeness, or usefulness of any information, apparatus, product, or process disclosed, or represents that its use would not infringe privately owned rights. Reference herein to any specific commercial product, process, or service by trade name, trademark, manufacturer, or otherwise, does not necessarily constitute or imply its endorsement, recommendation, or favoring by the United States Government or any agency thereof. The views and opinions of authors expressed herein do not necessarily state or reflect those of the United States Government or any agency thereof. 
Energy and Transpiration Sciences Division

\title{
Literature Review of Potential Thermally Activated Heat Pump Cycles
}

\author{
Ahmad Abu-Heiba
}

Date Published:

October $30^{\text {th }}, 2018$

Prepared by

OAK RIDGE NATIONAL LABORATORY

Oak Ridge, TN 37831-6283

managed by

UT-BATTELLE, LLC

for the

US DEPARTMENT OF ENERGY

under contract DE-AC05-00OR22725 



\section{CONTENTS}

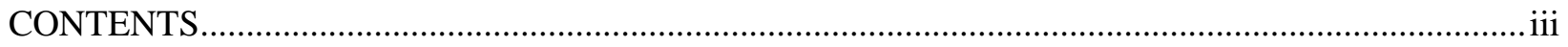

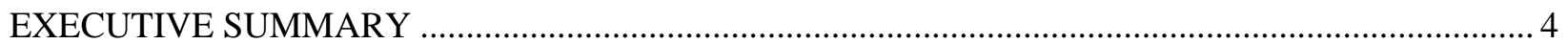

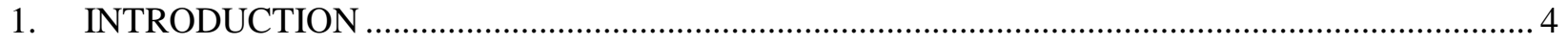

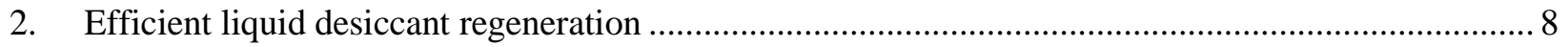

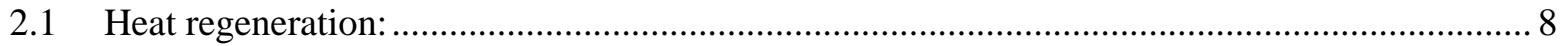

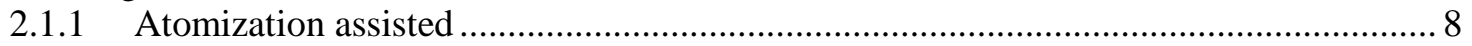

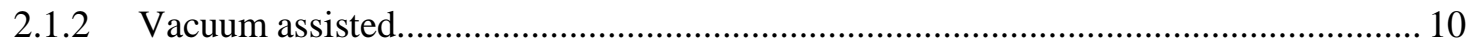

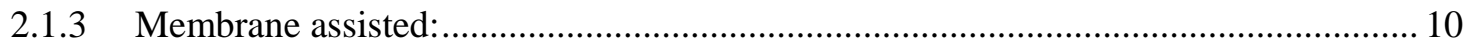

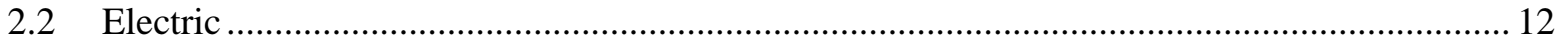

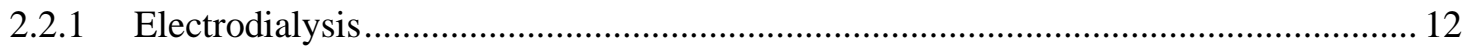

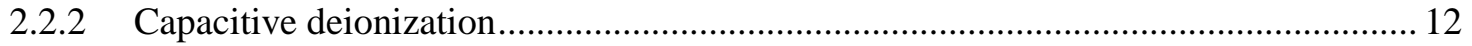

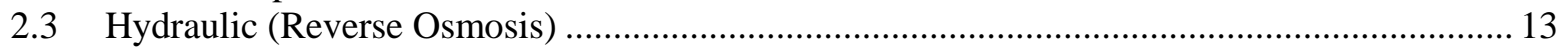

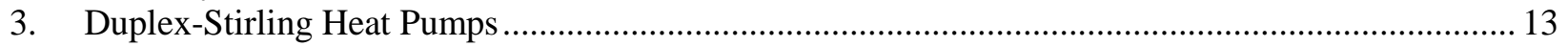

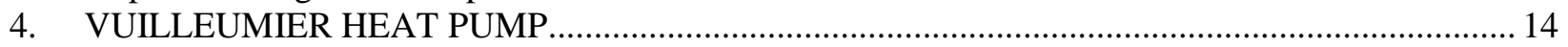

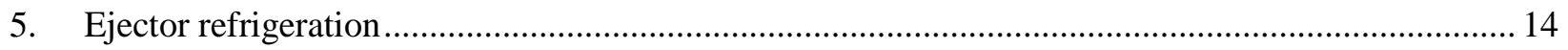

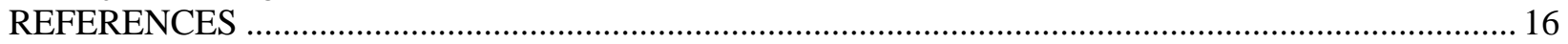




\section{EXECUTIVE SUMMARY}

Thermally driven heat pumps are gaining more strategic value as the electric grid moves toward decentralization. There exists a significant opportunity for them to raise the national primary energy efficiency. Historically, thermally driven heat pumps have been dominated by absorption. It is a mature technology, but it is limited by operational conditions and or cost and complexity. Other thermally driven heat pump cycles and technologies do exist that can provide practical solutions to maximizing the utilization of available heat. This report provides insights into the needed research to leverage the potential of those technologies. An extensive literature review on thermally driven heat pumps was conducted and four promising technologies were reported. The report highlights the research gaps that need to be addressed to mature those technologies. The findings are summarized below.

- Liquid desiccant regeneration

- Atomization improves the efficiency of the liquid desiccant regeneration process, but droplet carryover remains to be a major challenge to practical adoption of this technique.

- Regenerating the liquid desiccant under reduced ambient pressure reduces both the thermal energy and temperature that is needed to regenerate the desiccant under certain ambient condition. This in turn reduces the sensible cooling penalty. On the other hand, this reduction in thermal energy is offset by the energy required to reduce the pressure above the desiccant being regenerated. Research is needed to quantify the net benefit of regeneration under reduced pressure.

- Regeneration of liquid desiccant electrochemically has the advantages of the independence of energy consumption from the ambient conditions and the avoidance of heating the liquid desiccant being regenerated. The latter advantage eliminates the sensible cooling penalty. The available studies prove the feasibility of the concept, but it remains to be seen if these technologies can be designed for the high solute concentrations required for liquid desiccant operation in space dehumidification.

- Research is needed on reverse osmosis technique to characterize its energy performance. However, the high pressure needed to overcome the osmotic pressure will introduce challenges in practice and will add considerably to the cost of such regeneration system.

- Duplex-Stirling heat pump is promising

- Resonance tube coupling is a promising practical solution to overcome the challenges and limitations of mechanical coupling. Research is needed to better characterize the mechanisms of power transfer and to optimize operation.

- Ejector refrigeration

- A synergy of thermal storage and adjustable nozzle position has the potential to extend the operation envelope of ejector refrigeration machine to a practical limit. Fundamental research is needed to better characterize the realistic, transient performance of ejectors under varying conditions. 


\section{INTRODUCTION}

In its 2018 Annual Energy Outlook, EIA estimated the total energy consumption of space cooling, space heating, water heating and refrigeration in the residential sector of the USA at 11.11 Quads while the delivered energy consumption for the same end uses was estimated at 7.52 Quads. The difference between the "delivered" and the "total" is lost in transmission. This amounts to 3.59 Quads of lost energy in transmission, or $32 \%$ of the total energy consumption by those sectors. This ratio is a lot higher if we consider only space cooling as shown in Figure 1. The total energy consumption for space cooling is 2.07 Quads, while the delivered energy consumption for space cooling is 0.71 Quads: 66\% of total energy delivered for space cooling is lost.

Total vs. Delivered Energy Consumption

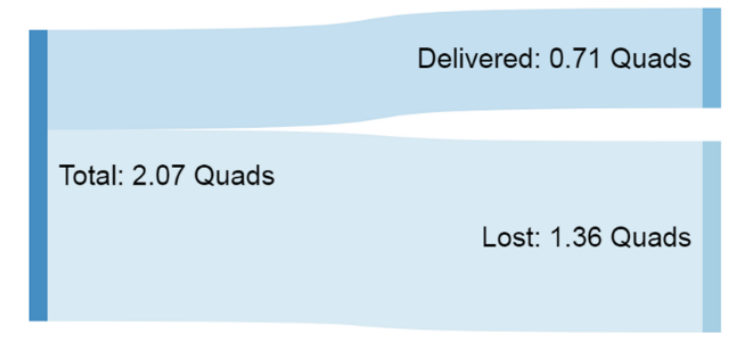

\section{Delivered Energy Consumption by Fuel}

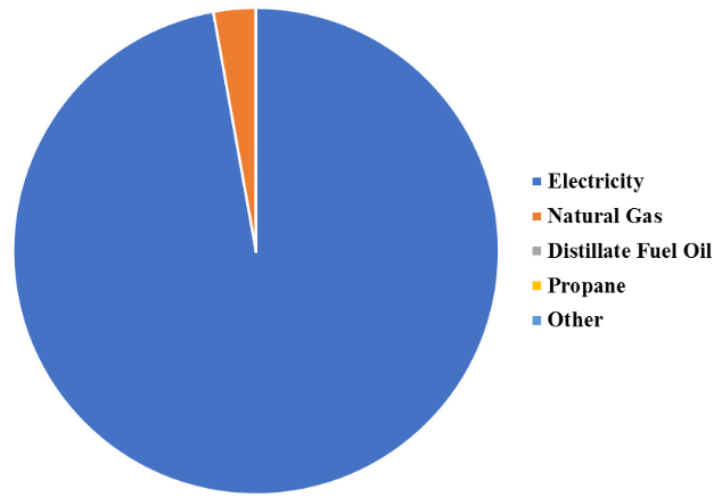

Figure 1. Total and Delivered energy consumption for the residential space cooling sector

The reason behind the higher loss ratio of space cooling is the fact that the delivered energy consumption for space cooling is practically entirely electric; 0.69 Quads of electric energy and 0.02 Quads of Natural Gas. The loss ratio for refrigeration, which uses exclusively electricity, is identical to space cooling. The ratio of loss is significantly less for space heating. As shown in Figure 2, the delivered energy consumption for space heating is 4.65 Quads, while the total energy consumption is 5.36 Quads. Only $13 \%$ of the total energy consumption for space heating is lost. This is because space heating is mostly primary energy driven; the delivered electric energy consumption for space heating is only 0.29 Quads, only $7 \%$ of the delivered energy consumption for space heating.

Total vs. Delivered Energy Consumption

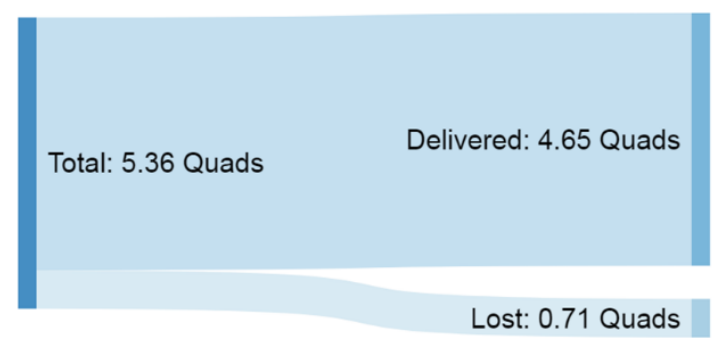

Delivered Energy Consumption by Fuel

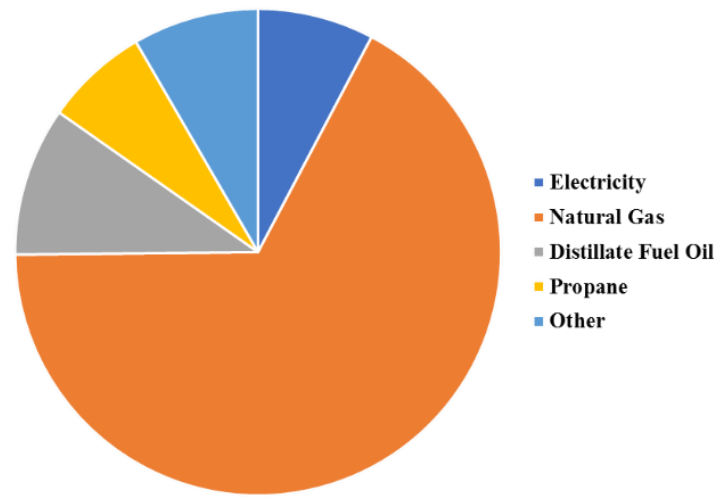

Figure 2. Total and Delivered energy consumption for the residential space heating sector 
The ratio of loss for water heating falls between space cooling and space heating at $32 \%$. Delivered electrical energy consumption for water heating is $25 \%$ of the delivered energy consumption for water heating as shown in Figure 3.

Total vs. Delivered Energy Consumption

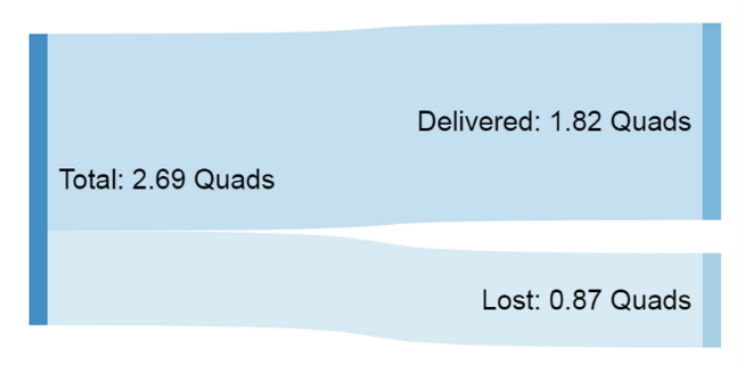

Delivered Energy Consumption by Fuel

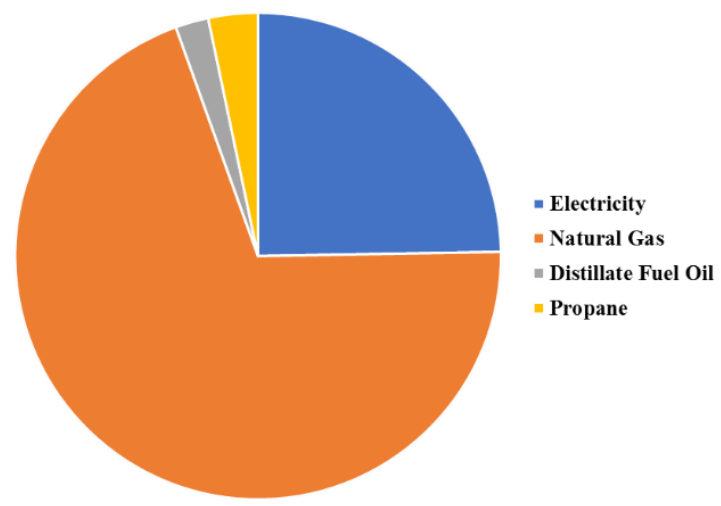

Figure 3. Total and Delivered energy consumption for the residential water heating sector

These figures show clear correlation between the losses of primary energy and fuel source. The more electrically driven an end-use is, the higher the primary energy loss due to the losses in generation and transmission. This correlation holds true for the commercial sector as well. There lies the opportunity for thermally driven heat pump technologies to greatly curb these losses.

Thermally driven heat pumps can increase the primary energy efficiency not only by eliminating the transmission loss associated with delivering electric energy, but also by: 1) integrating end uses, 2), and serving as bottoming cycle to harvest waste heat and turn into useful output. Integrating end uses is when a heat pump machine has a useful output other than heating and cooling. The most common example is heat pumps for space conditioning with water heating capability. Abu-Heiba, et al. [1] presented the results of evaluating the laboratory performance of gas fired heat pump. As illustrated in Figure 4, integrating water heating into the heat pump increased the primary energy efficiency of the machine by $34 \%$ to as much as $65 \%$.

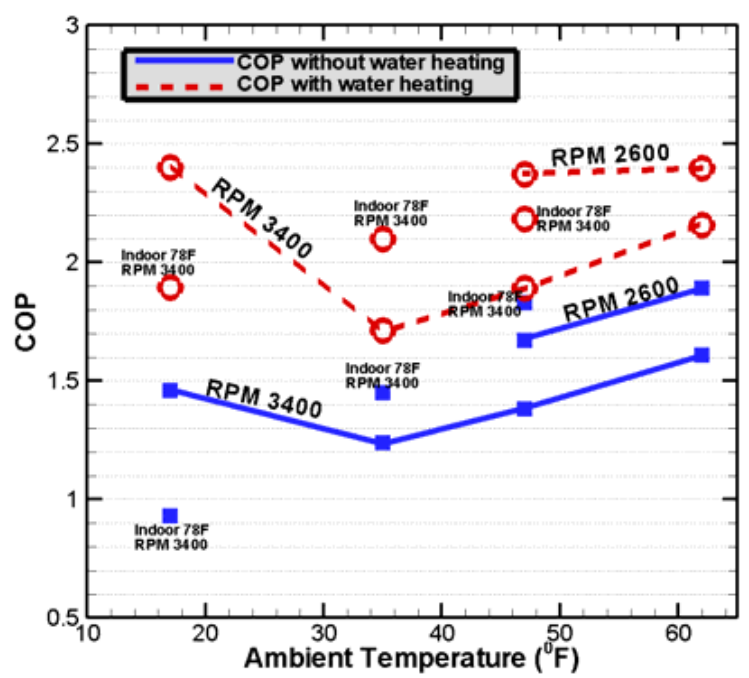

Figure 4. Primary energy coefficient of performance of gas fired heat pump with and without integrating water heating capability (figure is reprinted from [1]) 
Lawrence Livermore National Laboratory (LLNL) estimated a 2015 total amount of waste heat from all sectors of 59.1 Quads $^{1}$. This amounts to $60 \%$ of the total US energy consumption in 2015. ARPA-E estimates that approximately $75 \%$ of waste heat is at a temperature of $230{ }^{\circ} \mathrm{C}$ or less. While extracting work is difficult and inefficient at this temperature level, this temperature level is suitable for activation of some thermally driven heat pump technologies. This is a significant opportunity. Furthermore, thermally activated heat pumps reduce electric demand by as much as $80 \%$. Therefore, wide adoption of them is an effective means of relieving an already strained grid without additional generation capacity. Furthermore, with the spread of decentralized electric power generation, i.e. microgrids, waste heat will be closer to end use and using it to offset power demand will be both easier and impactful. Currently, the thermally driven heat pump sector is dominated by sorption technologies. Other cycles and technologies do exist with different maturity levels and degrees of active research. This report is meant to highlight research opportunities for low maturity but promising technologies and cycles, where research is most needed and potentially most impactful. It is not intended to be extensive reporting on the literature review of each thermally driven heat pump cycle.

A recent DOE published report investigated non-vapor compression technologies and scored them based on their potential [2]. Among the investigated technologies, several were thermally driven heat pump technologies. Short-, mid- and long-term R\&D initiatives that are needed to support further development of these technologies were recommended. The recommendations were the main guidance in narrowing the literature review scope of the current report. Besides recommendations of [2], general search for literature on thermally driven heat pump cycles and technologies was conducted through the Engineering Village database. This search was limited to literature published in the past 5 years and was aimed at finding breakthroughs in technologies that were not specified in the recommendations. Unsurprisingly, most of the results were sorption-related literature, with absorption-related literature body disproportionately larger than the adsorption-related one. In regards to absorption technology, the most notable innovation recently is the invention of an open absorption cycle for combined dehumidification, water heating, and evaporative cooling [3]. The cycle eliminates the shortcomings of conventional $\mathrm{LiBr}$ and Ammonia based absorption systems. A water heating prototype based on this cycle was built and its performance was evaluated in laboratory environment at ORNL. then performance was measured at a cycle thermal COP of 1.2 with a hot water delivery water temperature of $56^{\circ} \mathrm{C}$ and ambient air at $19^{\circ} \mathrm{C}$ and $49 \% \mathrm{RH}$ [4]. The consensus in literature regarding adsorption heat pumps is that they have high energy efficiency in heating but typically have COP less than unity in cooling. Several adsorption-based heating systems are commercialized in Europe. Those products have been demonstrated to have high COP as well as high seasonal efficiencies. However, little information is available on the specifics of the design that enabled these high efficiencies. The most recent work on cycle arrangement dates to the 1990s when [5] proposed a variation on the thermal wave cycle proposed by [6] and [7]. The thermal wave configuration achieves higher COP through improved heat recovery of the desorption heat. Active research in adsorption technology is focused on exploring better adsorbents such as zeolite, nano-porous materials and metal-hydrides, low-cost efficient heat exchanger designs and thermochemical energy storage.

The search results also suggested a significant interest in integrated combined cooling/heating and power generation technologies, mostly based on binary working fluids, i.e. Organic Rankine Cycle and absorption. Sizeable population of this literature body reported "new", "innovative" or "novel" cycles. Upon review, however, none was truly a new thermodynamic cycle, rather they were proposed architectures. None reported breakthrough efficiency levels, but most reported suitability for certain use cases. Gas engine driven related literature comprised a significant portion of the results. This literature was focused mainly on optimizing the control schemes for better load matching. Some of this literature reported on the use of engine driven heat pumps for produce drying and water heating applications.

\footnotetext{
${ }^{1}$ https://flowcharts.llnl.gov/content/assets/images/energy/us/Energy_US_2015.png
} 
This report will focus on low-maturity but promising technologies. In the following four sections, a detailed review of liquid desiccant regeneration technologies, Duplex-Stirling heat pumps, Vuilleumier heat pumps, and ejector refrigeration cycle is presented. At the end of each section, a brief commentary is included. The goal is to introduce a concise yet insightful outlook on the potential of these technologies, especially that they are currently under-investigated.

\section{EFFICIENT LIQUID DESICCANT REGENERATION}

Although it is not a heat pump "cycle", this topic is of prominent importance as separate sensible and latent air conditioning is becoming of rising significance and is expected to be a mainstream technology in the near future. Liquid desiccant regeneration has mainly been accomplished through addition of heat to evaporate some of the water content out of the diluted solution. Recent research efforts have largely focused on increasing the efficiency of the thermal regenerators. Disproportionally smaller portion of available research focused on developing alternative regeneration technologies of higher efficiency. The techniques that are reported on in the literature were compiled and classified as shown in Figure 5. In the following subsections, each of these technologies is reviewed.

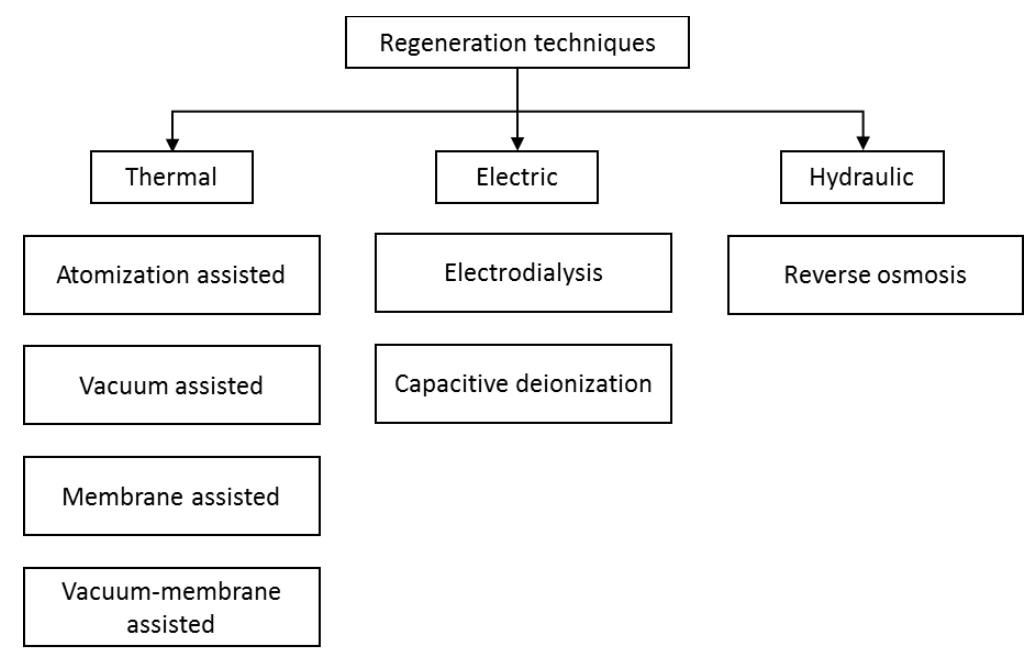

Figure 5. Classification of liquid desiccant regeneration techniques.

\subsection{HEAT REGENERATION:}

\subsubsection{Atomization assisted}

Yao [8] explained how ultrasound affects the diffusivity of solid-gas desiccant system and mass transfer coefficient in liquid-gas desiccant systems. The author mentions that for solid desiccant with pore size less than $200 \AA$, ultrasonic waves enhances moisture diffusivity into the solid desiccant due to the increase in the desiccant's temperature resulting from the thermal effect of the ultrasonic waves. For desiccants with larger pore size, diffusivity is enhanced due to a combination of both thermal and mechanical effects of the ultrasonic waves. On the gas side, the micro oscillations induced by the ultrasonic waves increases turbulence and reduces the thickness of the diffusion boundary layer. This reduces the mass transfer resistance and results in higher mass transfer rates. The enhancement is however affected by the temperature of the gas: the higher the temperature of the gas, the lower the enhancement. The deterioration of the enhancement of mass transfer is caused by increasing attenuation of the ultrasonic waves in higher-temperature gas. The magnitude of enhancement is also affected by the gas velocity. At lower gas velocities, the improvement of mass transfer is larger than at higher velocities. 
Beyond a certain velocity, the enhancement is negligible. In liquid-gas desiccant systems, atomization of the liquid desiccant into the gas increases the contact surface area by several orders of magnitude which enhances both heat and mass transfer. The paper reports that mass transfer coefficient increases with decreasing the droplet size. The rate of increase in mass transfer coefficient increases significantly when desiccant drop diameter is less than $50 \mu \mathrm{m}$. Although smaller droplet diameter results in higher mass transfer rates, the smallest droplet size is limited by practical considerations. The smaller the droplet size, the easier it is to be entrained and carried away by the gas stream. Li, et al. [9] designed, modeled and built a counter-flow ultrasonic atomization liquid desiccant regenerator. The liquid desiccant was Lithium Chloride and the gas was air. The mathematical model was a finite difference one and is detailed in the paper. The authors used the moisture removal rate (MRR) and the regeneration efficiency (RE) as the performance metrics of the regenerator. The analytical model was validated through a set of results of 24 experiments that were conducted at different inlet conditions: air mass flow rate, air temperature, air relative humidity, liquid desiccant mass flow rate, liquid desiccant concentration and liquid desiccant temperature. The model predicted the outlet air temperature to within $\pm 7 \%$, outlet air humidity and outlet desiccant temperature to within $\pm 5 \%$ and outlet desiccant concentration to within $\pm 3 \%$. The validated model was then used to investigate the effect of several parameters on the performance of the regeneration system. Interestingly, increasing the ratio of air flow rate to desiccant flow rate reduces the moisture removal rate but increases the outlet solution concentration. The effect of droplet diameter on MRR and RE was also investigated. The results showed negligible change in MRR and RE for droplet diameters of 50 to $100 \mu \mathrm{m}$. This, apparently, contradicts the results of Yao [8] that stipulate that MRR should significantly increase for droplet diameters less than $50 \mu \mathrm{m}$. This may be attributed to the fact that (Yao, 2010) was a purely analytical investigation, while the results in Li, Pan, Yao and Dong [9] is based on an actual system. Another important finding was that there exists a maximum droplet diameter beyond which no regeneration takes place. In an atomizing regenerator, as droplets diameter decreases, the droplet becomes more likely to be carried by the air and captured by the wall of the regenerator. Yang, et al. [10] introduced two parameters: droplets suspension rate and droplets capture rate. The droplets suspension rate is the ratio of the mass or volume of droplets that remain suspended in the regenerator chamber to the entire droplets mass or volume generated by the atomizing ultrasonic transducer. The droplets capture rate is the ratio of the mass or volume of droplets that have been captured by the walls of the regenerator chambers to the entire droplets mass or volume generated by the atomizing ultrasonic transducer. The paper presented analytical expressions to calculate both parameters as well as gas-liquid contact area. The paper then presented analytical expressions for the minimum required suspension rate and the minimum required contact area. These expressions were then used to optimize a design of a cross flow regenerator. An experimental set up was built per the optimized design. A 99\% efficient demister was included to reduce the toxicity risk of desiccant carryover. The performance of the optimized design was experimentally evaluated and compared to a baseline system that the authors had reported on previously. The optimized design achieved $220.02 \%$ improvement in dehumidification effectiveness, $45.87 \%$ improvement in desiccant consumption rate and required $31.58 \%$ less desiccant concentration level to accomplish the same dehumidification. While the specifics of the baseline system are unknown (publication was not accessible through ORNL's resources), the design methodology as detailed in the paper is a useful tool for regenerator designer. Yang, et al. [11] developed a model to predict the performance of atomizing regenerators. The paper gives the model the name Ideal Regeneration Model (IRM.) The model was used to predict the MRR and the DMFI of various systems reported on in open literature. The model predicts the ideal performance of a regenerator. It then uses one empirical parameter to compensate for the non-idealities of the modeled regenerator. The results showed the IRM prediction were within $\pm 20 \%$ of the reported experimental results, with an average deviation of $\pm 8.1 \%$. The IRM is mathematically simple and computationally inexpensive. However, the correction parameter is empirical and requires experimental data to infer its value. No analysis was made to correlate the correction parameter with the specifics of the modeled system. Therefore, the IRM is helpful in studying existing regenerators but not in the design process, unless such an analysis is made and can yield a universal correlation. 
While atomization improves the efficiency of the liquid desiccant process, droplet carryover remains to be a major challenge to practical adoption of this technique.

\subsubsection{Vacuum assisted}

Yon, et al. [12] proposed regenerating the desiccant thermally under reduced ambient pressure. A system was built with two connected compartments, both of which are under reduced ambient pressure. The first compartment contained a heating coil. The diluted Lithium Chloride desiccant solution is sprayed on the heating coil. Water evaporates out of the solution and is directed to the second compartment which contains a cooling coil. the water is condensed and discharged out of the system. The concentrated solution accumulates in the bottom of the first compartment and is pumped back to the air conditioning loop. The authors predicted the MRR through idealized heat and mass balance then applying an empirical correction factor. The correction factor was calculated as described in [10]. The model, empirically corrected, predicted the MRR to within $\pm 10 \%$ over a confidence interval of $94.12 \%$. The calibrated model was then used to parametrically investigate the performance of the regenerator. Required regeneration temperature of the proposed system was reduced to $25-30^{\circ} \mathrm{C}$ at regenerator operating ambient pressure of $1-2 \mathrm{kPa}$. The reduced generation temperature allows the use of low-grade heat to regenerate the desiccant, a benefit that should be considered when evaluating the feasibility of the regenerator, either on energy consumption basis or on economic basis. The performance of the proposed design was compared to packed-bed regenerator and $40.6 \%$ energy saving was reported. However, the paper did not quantify the energy saving that results from operation under reduced pressure in reference to operation under ambient pressure.

Regenerating the liquid desiccant under reduced pressure reduces both the thermal energy and temperature that needed to regenerate the desiccant under certain ambient condition. this in turn reduces the sensible cooling penalty. On the other hand, this reduction in thermal energy is offset by the energy required to reduce the pressure above the desiccant being regenerated. Research is needed to quantify the net benefit of regeneration under reduced pressure.

\subsubsection{Membrane assisted:}

Membrane assisted liquid desiccant regeneration has been reported to provide two main advantages over direct contact thermal regeneration: it can operate at a lower regeneration temperature and it eliminates carryover. Duong, et al. [13] reported on experimental investigation of $\mathrm{LiCl}$ membrane-assisted regeneration system Figure 6 . The authors focused on the effect of concentration polarization on the regeneration process. As the temperature of the solution increases, polarization of the solution increases which reduces the effective driving force. The authors showed that increasing the feed concentration to the regeneration unit increases specific energy consumption hyperbolically, while increasing the feed temperature decreases and increasing the cooling and purging flow rate decreased specific energy consumption. 


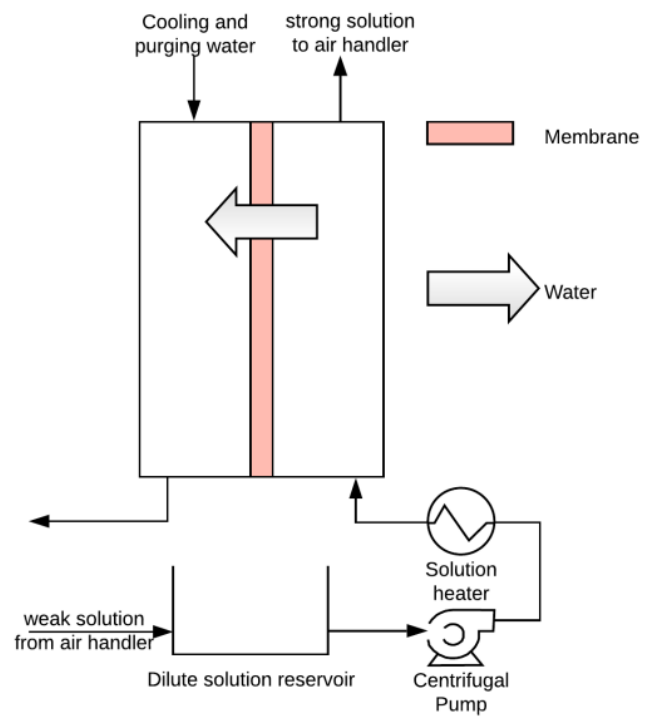

Figure 6. Membrane assisted liquid desiccant regeneration system

One of the main drawbacks of this arrangement is the significant amount of heat transfer across the membrane. Rattner, et al. [14] presented a heat and mass transfer model of a different arrangement for membrane assisted liquid desiccant regeneration system that mitigates the issue of heat transfer Figure 7. In this arrangement, an air gap was introduced between the dry side of the membrane and the weak solution flow channel wall. Water vapor leaves the solution stream being concentrated through the membrane and condenses on the back side of the flow channel of the weak solution. This arrangement not only eliminates heat transfer from the solution stream being concentrated and the weak solution but also recovers some of the latent heat of condensation into the solution to be heated.

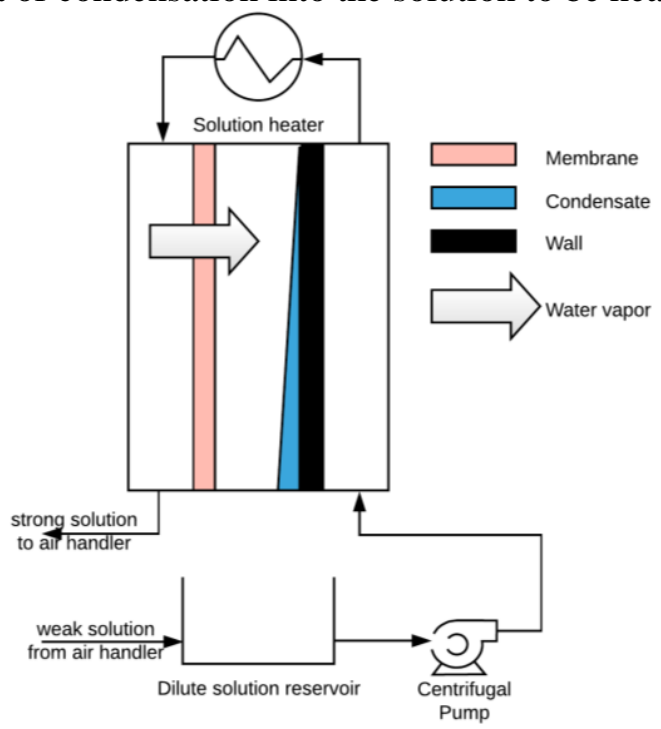

Figure 7. Air-gap membrane assisted liquid desiccant regeneration system

The results however showed that this system required higher regenerating temperature $\left(135^{\circ} \mathrm{C}\right)$ and had lower moisture removal rate $\left(11.4 \mathrm{mg} / \mathrm{min}-\mathrm{cm}^{3}\right)$ compared to other arrangements proposed in literature. The authors suggested that introducing forced convection in the air gap would substantially improve the moisture removal rate at the expense of increasing power consumption. 


\subsection{ELECTRIC}

\subsubsection{Electrodialysis}

Guo, et al. [15] experimentally evaluated the effect of solution flow rate, current density, concentration and concentration change on the performance of the LD ED regeneration system. the most important finding was the sensitivity of performance to the difference in concentration between the spent and regenerated solution streams. As this difference increases, water molecules migrate from the spent to the regenerated solution along with the salt molecules, which reduces the regeneration capacity of the system. This is due to the osmosis and electro-osmosis phenomena. The study reported current efficiency in the range of 55.17 to $73.54 \%$. in a follow up study, Al-Jubainawi, et al. [16] analytically and experimentally investigated the effects of osmosis, diffusion, electro-osmosis and ion migration on water and ion transport in LD ED regeneration system. The study concluded that the transport of water due to osmosis was more significant than the transport of salt ions, and that the water transport is directly proportional to the difference in concentrations between the two solution streams and is inversely proportional to the applied current. This implies that improvement in performance would be gained if the solution streams were in counter flow arrangement.

\subsubsection{Capacitive deionization}

Capacitive Deionization (CDI) is a separation technology that relies on applying electrical potential difference over two electrodes. The technology was introduced in 1960 for water desalination by "electrochemical demineralization". As shown in Figure 8, water flows between two electrodes that are connected to an electric power source. The electric field between the electrodes ionizes the salt molecules. The anions and the cations then transport through the water and are adsorbed onto the anode and the cathode respectively, with pure water as the by product.
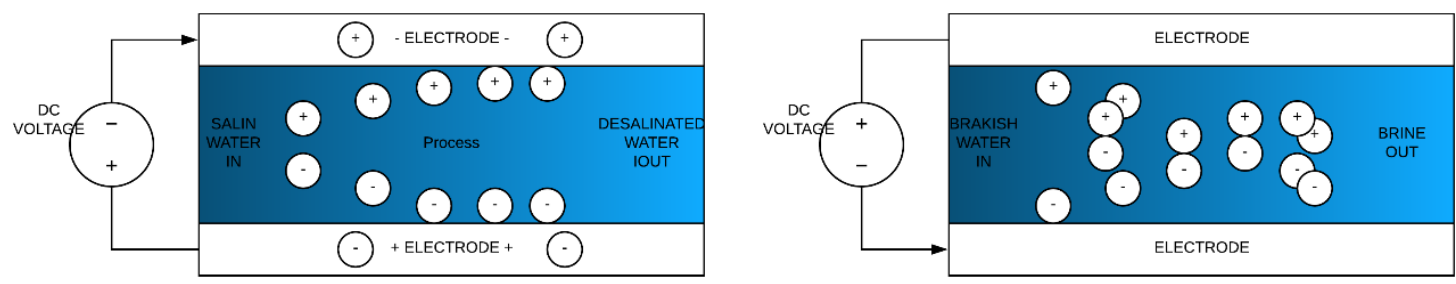

Figure 8. Salt ions are separated from water and adsorbed on the electrodes (left). When voltage is reversed, electrodes are regenerated (right)

One study reported on adopting the CDI technology for liquid desiccant regeneration [17]. The paper presented an analytical model of Photovoltaic powered regenerator. The model was run parametrically using assumed values for some of the unknown parameters. The results showed that there was an initial liquid desiccant concentration where using a solar heater is more efficient than using the PV powered CDI. The only experimental result that was presented was the charge efficiency against the initial concentration of the liquid desiccant to be regenerated. The charge efficiency is a measure of how effectively ions are adsorbed on the electrodes for a given applied current. The charge efficiency was found to have a maximum at some liquid desiccant concentration. On either side of this concentration, charge efficiency drops. At lower concentrations, there isn't enough ions to be adsorbed. At high concentrations, ions are initially adsorbed on the electrodes. These charged ions are attracted and attract oppositely charged ions in the liquid desiccant between the two electrodes. Some of these ions then inevitably return to the bulk of the fluid, decreasing the charge efficiency. The authors suggested in the conclusion to place ion-exchange membranes in between the electrodes and the bulk fluid. this prevents the adsorbed ions from returning to the bulk solution. 
Regeneration of liquid desiccant using electric current has the advantages of the independence of energy consumption from the ambient conditions and the avoidance of heating the liquid desiccant being regenerated. The latter advantage eliminates the sensible cooling penalty. All experimental work that was done on both electrodialysis and capacitive deionization were conducted using units that were designed for the low solute concentration levels typically encountered in water desalination. Therefore, no generalization as what efficiency levels these technologies can achieve can be drawn. The studies proved the feasibility of the concept, but it remains to be seen if these technologies can be designed for the high solute concentrations required for liquid desiccant operation in space dehumidification.

\subsection{HYDRAULIC (REVERSE OSMOSIS)}

There are few literatures available on the use of Reverse Osmosis for liquid desiccant regeneration. AlFarayedhi, et al. [18] analytically developed correlations to predict the minimum pressure needed to regenerate $\mathrm{LiCl}$ and $\mathrm{CaCl}_{2}$ between known concentration differences. The model is valid for concentration range of 5 to $45 \%$ by weight. The correlations include the effect of temperature of the liquid desiccant on the required minimum pressure. Al-Sulaiman, et al. [19] conducted an analytical analysis of RO liquid desiccant regeneration system. The study found that although the minimum pressure required to regenerate the solution was $24.4 \mathrm{MPa}$, in practice double that pressure was required.

Research is needed on this technique to characterize its energy performance. The high pressure needed to overcome the osmotic pressure will introduce challenges in practice and will add considerably to the cost of such regeneration system.

\section{DUPLEX-STIRLING HEAT PUMPS}

In the late 1980s and early 1990s, several free-piston duplex Stirling heat pump prototypes were built by Sunpower Inc., founded by William Beale the inventor of the free-piston Stirling engine technology, ranging in in size between 60 and $250 \mathrm{~W}$ [20-23]. Their estimates showed that the COP of such heat pump could potentially reach $40 \%$ of Carnot. It is not clear why Sunpower Inc. did not commercialize the heat pump. They are now focused on Cryocooling using the same technology. Since then till recently, research in Stirling cycle has been focused on the development of free-piston Stirling engines with almost no research on duplex Stirling heat pumps. Erbay, et al. [24] benchmarked the performance of duplex Stirling refrigerator through thermodynamic analysis of the engine and the heat pump separately. The outcome of the study is a helpful guide for the thermal design of duplex Stirling heat pumps. Doğan, et al. [25] built on that analysis and investigated the effect of 9 combinations of working pairs of $\mathrm{CO}_{2}, \mathrm{He}$ and $\mathrm{H}_{2}$ on the performance of duplex Stirling heat pumps. The study identified the COP $>1$ envelope of each working pair. $\mathrm{Hu}$, et al. [26] attributed the difficulty in having a practical working duplex Stirling heat pump to the deviation of real machines from design. The paper demonstrated how slight variations in working conditions such as temperature had a large effect of the performance of the heat pump. The paper proposed varying the charging pressure in response to operating conditions to mitigate the effect of operating at off-design conditions. The concept was verified to be effective analytically, but the was not verified experimentally. One of the most significant conclusions of this paper was that the main technical barrier to development of this technology was the coupling of the engine and the heat pump. in order to tune the coupling under as wide of operating envelope as possible, the coupling piston must be very large. This increases the mechanical resistance significantly and causes vibrations and loss of efficiency. Li, et al. [27] proposed coupling the engine to the heat pump through a resonance tube to eliminate the penalties associated with using a coupling-piston. The concept is to transfer the power generated in the engine to the heat pump through traveling pressure waves in a tube that is open to the displacer of the engine at one 
end and open to the displacer of the heat pump at the other. This eliminates the coupling piston altogether. The frequency of the traveling pressure wave can be externally influenced to ensure that the engine, pressure wave and the heat pump are running at the same frequency. The authors did experimental study to proof the concept. They then analyzed the results and identified the causes of the losses. The authors then presented an analytical model of the proposed configuration and used it to optimize a design of the configuration.

Coupling the engine to the heat pump through resonance tube is a promising practical solution.

Research is needed to better characterize the mechanisms of power transfer and optimize them.

\section{VUILLEUMIER HEAT PUMP}

During the 1990s, there was an interest in this technology and several prototypes were built. They demonstrated heating COP ranging from 1.4 to 1.6 but their cooling COP was less than one. A period of stagnancy then followed for about two decades. Available literature is mostly analytical and is focused on optimization based on either thermodynamic or system models. like the Duplex-Stirling machine, the main technical challenge to realizing a working machine has been the coupling of the engine to the heat pump. Thermolift, a startup based in the USA, is currently developing a Vuilleumier heat pump and is targeting heating COP of 1.6 to 2.2 and cooling COP of 0.8 to 1.2. The enabling innovation is using electromechanical rather than mechanical coupling. This decouples the motion of the engine displacer from the motion of the heat pump displacer and allows non-sinusoidal motion, which in turn could increase energy utilization. Thermolift Vuilleumier heat pump prototype was evaluated at ORNL in August. Until the time of writing this report, the results had not yet been published.

\section{EJECTOR REFRIGERATION}

Despite its, traditionally, poor performance under off-design conditions, the ejector refrigeration remains an attractive cycle for cooling applications. In fact, due to several reasons, interest in this technology is expected to increase dramatically. Ejector refrigeration machines are simple in construction with minimal number of moving parts or even no moving parts, and therefore could be manufactured at low cost and can run almost maintenance-free. They can employ one of many refrigerants or water as working fluid and they can be activated by heat at low temperature. Interest in $\mathrm{CO}_{2}$ refrigeration machines has spiked the interest in ejector technology. Ejector refrigeration machines will directly make use of the advancements in ejector technology to overcome their traditional technical barriers. The rise of thermal storage could also be a significant factor in advancing ejector-based technology if such machines are designed to utilize thermal storage to lessen, if not eliminate, the negative impact of off-design operating conditions. Dong, et al. [28] presented the results of an experimental evaluation of the effect of nozzle position on the performance of an ejector cooling machine employing water as the working fluid. the machine achieved a COP of 1.37 driven by a high temperature source of $130{ }^{\circ} \mathrm{C}$ and a low temperature sink of $15{ }^{\circ} \mathrm{C}$. This represents a 54\% Carnot efficiency. The machine used an adjustable nozzle which enabled a great flexibility of the machine in responding to varying sink and source temperatures. Besagni, et al. [29] presented an extensive review on ejector refrigeration. The paper presented a time trend of COP of several ejector refrigeration technologies. it showed that the COP of single ejector refrigeration machine had grown from 0.12 in 1995 to 0.75 in 2015 . The authors recommended research and development needs to advance the ejector technologies in general. The recommendation centered around 
developing more realistic models, two-phase transient, of ejectors and ejector machines that capture the realistic dynamics those components and machines.

A synergy of thermal storage and adjustable nozzle has the potential to extend the operation envelope of ejector refrigeration machine to a practical limit. Fundamental research is needed to better characterize the realistic, transient performance of ejectors under varying conditions. 


\section{REFERENCES}

[1] Abu-Heiba, A., Vineyard, E. A., and Momen, A., 2015, "Multi-Function Gas Fired Heat Pump," No. ORNL/TM-2015/701; Other: ED2701000; CEED210; CRADA/NFE-10-02997 United States 10.2172/1254790 Other: ED2701000; CEED210; CRADA/NFE-10-02997 ORNL English, ; Oak Ridge National Lab. (ORNL), Oak Ridge, TN (United States). Building Technologies Research and Integration Center (BTRIC).

[2] Goetzler, W., Zogg, R., Young, J., and Johnson, C., 2014, "Energy Savings Potential and RD\&D Opputunities for Non-Vapor Compression HVAC Technologies."

[3] Moghaddam, S., Chugh, D., Nasrisfahani, R., Bigham, S., Fazeli, S. A., Yu, D., Mortazavi, M., and Abdelazi, O., 2016, "Open Absorption Cycle for Combined Dehumidification, Water Heating, and Evaporative Cooling," University of Florida Research Foundation IncUT-Battelle LLC

[4] Devesh Chugh, K. G., Ahmad Abu-Heiba, Morteza Alipanah, Abdy Fazeli, Richard Rode, Michael Schmid,Viral Patel, and Saeed Moghaddam, 2018, "Experimental evaluation of a semi-open membranebased absorption heat pump system utilizing ionic liquids,"Applied Energy.

[5] Critoph, R. E., 1999, "Forced convection adsorption cycle with packed bed heat regeneration: Cycle à adsorption à convection forcée avec régénération thermique du lit fixe," International Journal of Refrigeration, 22(1), pp. 38-46.

[6] Shelton, S. V., 1986, "Solid adsorbent heat pump system,"USA.

[7] Tchernev, D. I., 1987, "Heat pump energized by low-grade heat source,"USA.

[8] Yao, Y., 2010, "Using power ultrasound for the regeneration of dehumidizers in desiccant airconditioning systems: A review of prospective studies and unexplored issues," Renewable and Sustainable Energy Reviews, 14(7), pp. 1860-1873.

[9] Li, W., Pan, Y., Yao, Y., and Dong, M., 2018, "Modeling and parametric study of the ultrasonic atomization regeneration of desiccant solution," International Journal of Heat and Mass Transfer, 127, pp. 687-702.

[10] Yang, Z., Zhang, K., Yang, M., and Lian, Z., 2014, "Improvement of the ultrasonic atomization liquid desiccant dehumidification system," Energy and Buildings, 85, pp. 145-154.

[11] Yang, Z., Zhang, K., Hwang, Y., and Lian, Z., 2016, "Performance investigation on the ultrasonic atomization liquid desiccant regeneration system," Applied Energy, 171, pp. 12-25.

[12] Yon, H. R., Cai, W., Wang, Y., and Shen, S., 2018, "Performance investigation on a novel liquid desiccant regeneration system operating in vacuum condition," Applied Energy, 211, pp. 249-258.

[13] Duong, H. C., Hai, F. I., Al-Jubainawi, A., Ma, Z., He, T., and Nghiem, L. D., 2017, "Liquid desiccant lithium chloride regeneration by membrane distillation for air conditioning," Separation and Purification Technology, 177, pp. 121-128.

[14] Rattner, A. S., Nagavarapu, A. K., Garimella, S., and Fuller, T. F., 2011, "Modeling of a flat plate membrane-distillation system for liquid desiccant regeneration in air-conditioning applications," International Journal of Heat and Mass Transfer, 54(15-16), pp. 3650-3660.

[15] Guo, Y., Ma, Z., Al-Jubainawi, A., Cooper, P., and Nghiem, L. D., 2016, "Using electrodialysis for regeneration of aqueous lithium chloride solution in liquid desiccant air conditioning systems," Energy and Buildings, 116, pp. 285-295.

[16] Al-Jubainawi, A., Ma, Z., Guo, Y., Nghiem, L. D., Cooper, P., and Li, W., 2017, "Factors governing mass transfer during membrane electrodialysis regeneration of $\mathrm{LiCl}$ solution for liquid desiccant dehumidification systems," Sustainable Cities and Society, 28, pp. 30-41. 
[17] Yang, Q., Li, X.-W., and Fang, A.-M., 2017, "Photovoltaic capacitive deionization regeneration method for liquid desiccant cooling system," Applied Thermal Engineering, 117, pp. 204-212.

[18] Al-Farayedhi, A. A., Gandhidasan, P., and Younus Ahmed, S., 1999, "Regeneration of liquid desiccants using membrane technology," Energy Conversion and Management, 40(13), pp. 1405-1411.

[19] Al-Sulaiman, F. A., Gandhidasan, P., and Zubair, S. M., 2007, "Liquid desiccant based two-stage evaporative cooling system using reverse osmosis (RO) process for regeneration," Applied Thermal Engineering, 27(14), pp. 2449-2454.

[20] L. B. Penswick, and Urieli, I., 1984, "Duplex Stirling Machines," 19th Annual Intersociety Energy Conversion Engineering ConferenceSan Francisco, California.

[21] D. M. Berchowitz, and Shonder, J., 1991, "Estimated size and performance of a natural gas fired duplex Stirling for domestic refrigeration applications," 18th International Congress on RefrigerationMontreal, Canada.

[22] Berchowitz, D. M., 1993, "Free-Piston Rankine Compression and Stirling Cycle Machines for Domestic Refrigeration," Greenpeace Ozone Safe ConferenceWashington, DC.

[23] Chen, G., and Beale, W. T., 1993, "Thermally Actuated Duplex Free-Piston Stirling System for Domestic Cooling and Heating Applications," International Conference on CFCs and Halon AlternativesBeijin, China.

[24] Erbay, L. B., Ozturk, M. M., and Doğan, B., 2017, "Overall performance of the duplex Stirling refrigerator," Energy Conversion and Management, 133, pp. 196-203.

[25] Doğan, B., Ozturk, M. M., and Erbay, L. B., 2018, "Effect of working fluid on the performance of the duplex Stirling refrigerator," Journal of Cleaner Production, 189, pp. 98-107.

[26] Hu, J. Y., Luo, E. C., Dai, W., and Zhang, L. M., 2017, "Parameter sensitivity analysis of duplex Stirling coolers," Applied Energy, 190, pp. 1039-1046.

[27] Li, X., Liu, B., Yu, G., Dai, W., Hu, J., Luo, E., and Li, H., 2017, "Experimental validation and numeric optimization of a resonance tube-coupled duplex Stirling cooler," Applied Energy, 207, pp. 604612.

[28] Dong, J., Pounds, D. A., Cheng, P., and Ma, H. B., 2012, "An Experimental Investigation of Steam Ejector Refrigeration Systems," Journal of Thermal Science and Engineering Applications, 4(3).

[29] Besagni, G., Mereu, R., and Inzoli, F., 2016, "Ejector refrigeration: A comprehensive review," Renewable and Sustainable Energy Reviews, 53, pp. 373-407. 